\title{
Severe drought strongly reduces water use and its recovery ability of mature Mongolian Scots pine (Pinus sylvestris var. mongolica Litv.) in a semi-arid sandy environment of northern China
}

\author{
DANG Hongzhong $^{1 *}$, ZHANG Lizhen ${ }^{2}$, YANG Wenbin ${ }^{1}$, FENG Jinchao ${ }^{1}$, HAN Hui ${ }^{3}$, CHEN \\ Yiben $^{4}$ \\ ${ }^{1}$ Institute of Desertification Studies, Chinese Academy of Forestry, Beijing 100091, China; \\ ${ }^{2}$ Institute of Resources and Environment, China Agricultural University, Beijing 100094, China; \\ ${ }^{3}$ Institute of Sand Fixation and Afforestation of Liaoning Province, Fuxin 123000, China; \\ ${ }^{4}$ Beijing Forestry University, Beijing 100083, China
}

\begin{abstract}
Trees growing in a semi-arid sandy environment are often exposed to drought conditions due to seasonal variations in precipitation, low soil water retention and deep groundwater level. However, adaptability and plasticity of individuals to the changing drought conditions greatly vary among tree species. In this study, we estimated water use $\left(T_{\mathrm{s}}\right)$ of Mongolian Scots pine (MSP; Pinus sylvestris var. mongolica Litv.) based on sap flux density measurements over four successive years (2013-2016) that exhibited significant fluctuations in precipitation in a semi-arid sandy environment of northern China. The results showed that fluctuations in daily $T_{\mathrm{s}}$ synchronously varied with dry-wet cycles of soil moisture over the study period. The daily ratio of water use to reference evapotranspiration $\left(T_{\mathrm{s}} / \mathrm{ET}_{0}\right)$ on sunny days in each year showed a negative linear relationship with the severity of drought in the upper soil layer $(0-1$ $\mathrm{m} ; \mathrm{P}<0.01)$. The decrease in $T \mathrm{~s}$ induced by erratic drought during the growing season recovered due to precipitation. However, this recovery ability failed under prolonged and severe droughts. The $T_{\mathrm{s}} / \mathrm{ET}_{0}$ ratio significantly declined with the progressive reduction in the groundwater level $\left(g_{\mathrm{w}}\right)$ over the study period $(P<0.01)$. We concluded that the upper soil layer contributed the most to the $T_{\mathrm{s}}$ of MSP during the growing season. The severity and duration of droughts in this layer greatly reduced $T_{\mathrm{s}}$. Nevertheless, $g_{\mathrm{w}}$ determined whether the $T_{\mathrm{s}}$ could completely recover after the alleviation of long-term soil drought. These results provide practical information for optimizing MSP management to stop ongoing degradation in the semi-arid sandy environments.
\end{abstract}

Keywords: groundwater; soil water availability; water stress; sap flow; reference evapotranspiration

Citation: DANG Hongzhong, ZHANG Lizhen, YANG Wenbin, FENG Jinchao, HAN Hui, CHEN Yiben. 2019. Severe drought strongly reduces water use and its recovery ability of mature Mongolian Scots pine (Pinus sylvestris var. mongolica Litv.) in a semi-arid sandy environment of northern China. Journal of Arid Land, 11(6): 880-891. https://doi.org/10.1007/s40333-019-0029-2

\section{Introduction}

Reforestation has been widely used in semi-arid areas to control soil erosion and to capture

\footnotetext{
*Corresponding author: DANG Hongzhong (E-mail: hzdang@caf.ac.cn)

Received 2018-02-07; revised 2019-10-15; accepted 2019-10-28

(C) Xinjiang Institute of Ecology and Geography, Chinese Academy of Sciences, Science Press and Springer-Verlag GmbH Germany, part of Springer Nature 2019
} 
carbon for regional sustainability (D'Odorico and Porporato, 2006). However, tree growth in water-limited ecosystems is often exposed to significant environment-related challenges, such as drought (Mereu et al., 2009; Wesche et al., 2011; Su et al., 2014). Many environmental factors influence the survival and growth of trees in semi-arid areas, for instance, amount and variability of precipitation, soil water storage and availability of groundwater (Meinzer et al., 2006; Zhang Jinhu et al., 2018). Increasing frequency and severity of drought are known to have severe negative impacts on forest ecosystems and increase mortality rate of trees (Leo et al., 2013; Barbeta et al., 2015; Gazol et al., 2018). Impacts of drought on ecological and hydrological processes associated with trees in fragile ecosystems have attracted sustained and intensive attention (Bovard et al., 2005). Quantification of tree water use and its long-term response to drought can aid in understanding of how trees adapt to a changing environment.

Mongolian Scots pine (MSP; Pinus sylvestris var. mongolica Litv.) is widely distributed in the Da Higgan Ling Mountains $\left(50^{\circ} 10^{\prime}-53^{\circ} 33^{\prime} \mathrm{N}, 121^{\circ} 11^{\prime}-127^{\circ} 10^{\prime} \mathrm{E}\right)$ of northern China and in parts of Russia and Mongolia (Zhu et al., 2008; Zheng et al., 2012). MSP is a popular tree species for reforestation in northern China due to its high tolerance to both drought and low temperature. Total area of MSP plantation established by the Three-North Shelter Forest Program since 1978 exceeds $6.7 \times 10^{5} \mathrm{hm}^{2}$ in northern China (Zheng et al., 2012), which greatly contributes to the control of desertification. However, severe degradation in the artificial forests of MSP has occurred since the mid-1990s, and this degradation is characterized by poor health and a large number of deaths of MSP, particularly in the Horqin Sandy Land in northern China (Jiao, 2001; Zhu et al., 2008).

Degradation in the artificial forests of MSP in the Horqin Sandy Land is mainly attributed to the high inter-annual and intra-seasonal variations in precipitation and declining groundwater level (Jiao, 1989; Song et al., 2014). These impacts seems reasonable because MSP is a shallow-rooted species with more than $85 \%$ of roots distributed in the upper $0-40 \mathrm{~cm}$ soil layer in this region, and root density sharply decreased below $100 \mathrm{~cm}$ soil layer ( $\mathrm{Su}$ et al., 2006), which limits water absorption from deep soil. However, without frequent and long-term monitoring of tree water use and environmental variables, we still have limited knowledge of how and to what extent precipitation-dominated water availability is responsible for the degradation of MSP. Therefore, this study aims to: (1) quantify sap flux density and daily water use of MSP over four successive years (2013-2016) with contrasting precipitation fluctuations; (2) determine the linkage between variation in the daily tree water use and intra-seasonal dry-wet cycles of soil moisture; and (3) investigate the ability of tree water use recovery after long-term successive and severe droughts.

\section{Materials and methods}

\subsection{Study area}

The study was carried out at the Zhanggutai National Desertification Control Trial Station in the Horqin Sandy Land, northern China $\left(42^{\circ} 43^{\prime} \mathrm{N}, 122^{\circ} 22^{\prime} \mathrm{E}\right.$; $226.5 \mathrm{~m}$ a.s.1.). The experiment was conducted in the artificial forests (an area of $40 \mathrm{hm}^{2}$ ) with 35-year-old MSPs during 2013-2016. Tree density was 625 plants $/ \mathrm{hm}^{2}$ with a $4-\mathrm{m}$ row spacing between individual trees. The study area has a semi-arid, continental climate with an annual mean temperature of $7.9^{\circ} \mathrm{C}$, a frost-free period of 150-160 d, a mean annual pan evaporation of $1553 \mathrm{~mm}$ and an annual precipitation of $475 \mathrm{~mm}$ (with 60\%-70\% falling from June to August) over the last 30 a (1983-2012; Zhu et al., 2005).

After 1983, there were 9 consecutive dry years from 1996 to 2004 with below mean value of the annual precipitation (Fig. 1a). The annual mean temperature over the last 34 years has significantly increased at a rate of $0.03^{\circ} \mathrm{C} / \mathrm{a}$ (Fig. 1b).

Soil has a sedimentary aeolian sand layer that exceeds $3 \mathrm{~m}$ and an ancient alluvial sand layer that exceeds $126 \mathrm{~m}$ (Jiao, 1989). Bulk densities in the 0.0-0.4 and 0.0-2.0 m soil layers are 1.47 and $1.57 \mathrm{~g} / \mathrm{cm}^{3}$, respectively. Soils in the $0.0-0.4 \mathrm{~m}$ layer comprise $87 \%$ sand $(>0.050 \mathrm{~mm}), 9 \%$ silt $(0.050-0.002 \mathrm{~mm})$ and $4 \%$ clay $(<0.002 \mathrm{~mm})$. Sand, silt and clay account for $91 \%, 4 \%$ and 
$5 \%$ in the $0.0-2.0 \mathrm{~m}$ soil layer, respectively. Organic matter content in the $0.0-0.4 \mathrm{~cm}$ soil layer is approximately $1.54 \mathrm{~g} / \mathrm{kg}$ and decreases to $0.76 \mathrm{~g} / \mathrm{kg}$ in the $0.0-2.0 \mathrm{~m}$ soil layer. The understory plant species are Acer pictum subsp. mono Maxim, Crataegus pinnatifida var. major N. E. Brown., Lespedeza bicolor Turcz., Artemisia halodendron Turcz et Bess. and Cleistogenes chinensis Maxim.

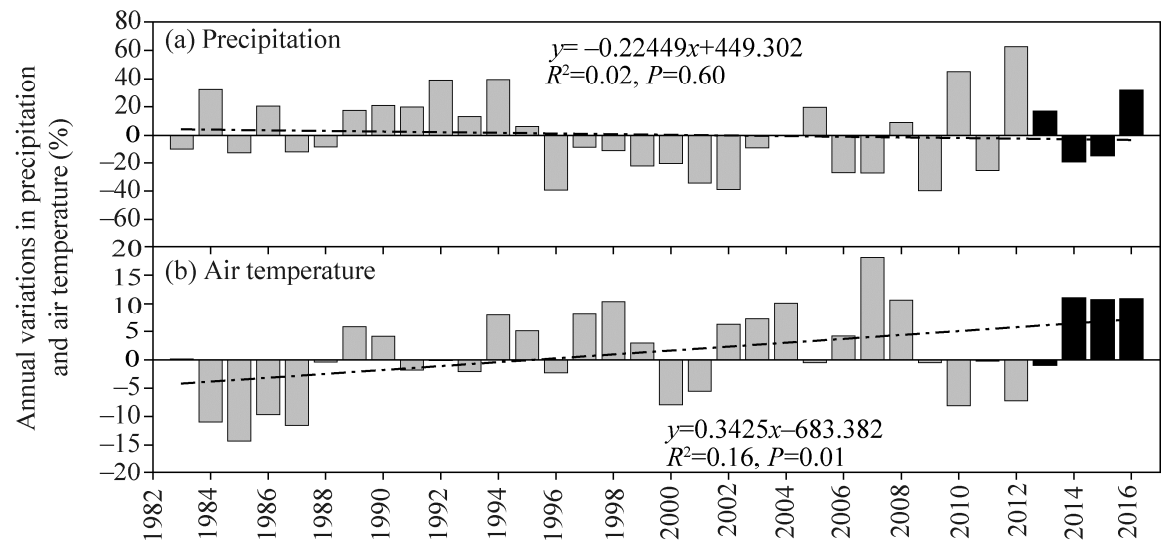

Fig. 1 Annual variations in (a) precipitation and (b) air temperature at the Zhanggutai National Desertification Control Trial Station in the Horqin Sandy Land, northern China during 1983-2016. Gray columns show the data before the experiment (1983-2012) and black columns are the data of the experiment from 2013 to 2016. Dashed lines are linear regressions over the entire period.

\subsection{Experimental design and measurements}

A $400 \mathrm{~m}^{2}$ plot $(20 \mathrm{~m} \times 20 \mathrm{~m})$ containing 25 even-aged trees surrounded by a wire fence was selected (Fig. 2). Growth of trees in the experiment was normal in 2013 and 2014, but in 2015 and 2016 , leaves from the upper canopy turned slightly gray. Information of sampled trees is given in Table 1. Due to the damage of instrument installed in the trunk, the number of tree samples decreased to 11 in 2016. Diameter at breast height (DBH) was measured by a diameter tape, and tree height was measured by an altimeter after the growing period. Thicknesses of bark, sapwood and heartwood were measured by a sampling core near the installed position of sensors with a Pressler incremental borer after the experiment. We measured the thickness by a Vernier caliper with tissue boundaries identified based on the color that is a yellow-white sapwood tissue and a $\tan$ heartwood tissue. We used methyl orange solution to help define the interface where boundary was indistinct. $\mathrm{DBH}(P=0.59)$ and sapwood width $(P=0.55)$ of sampled trees during 2013-2016 were not significantly different, indicating a satisfactory uniformity of sample trees.

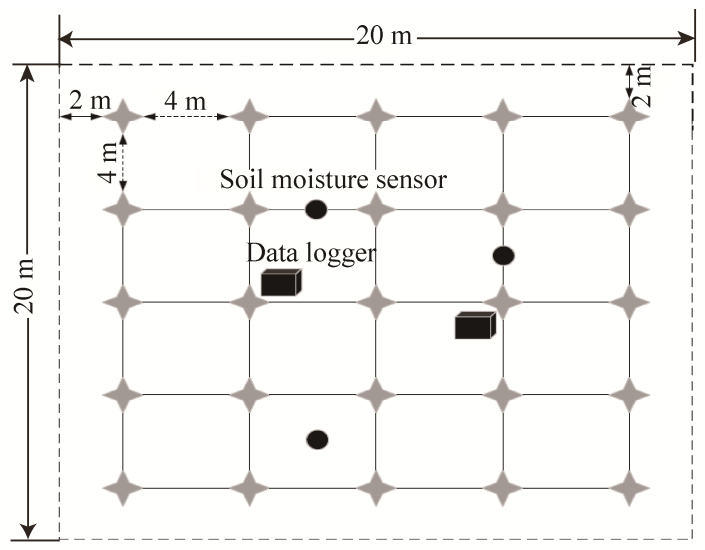

Fig. 2 Sketch of sample trees (gray stars) planted in a $4 \mathrm{~m} \times 4 \mathrm{~m}$ spaced square grid. Locations of soil moisture sensors and data logger are shown. Dashed line is the border fence. 
Table 1 Information of sample trees during 2013-2016

\begin{tabular}{|c|c|c|c|c|c|c|c|}
\hline \multirow{2}{*}{ Year } & \multicolumn{3}{|c|}{ DBH (cm) } & \multirow{2}{*}{$H(\mathrm{~m})$} & \multirow{2}{*}{$H_{\mathrm{b}}(\mathrm{m})$} & \multirow{2}{*}{$\mathrm{SW}(\mathrm{cm})$} & \multirow{2}{*}{$A_{\mathrm{s}}\left(\mathrm{cm}^{2}\right)$} \\
\hline & Mean \pm SD & $Q_{1}$ & $Q_{3}$ & & & & \\
\hline $2013(n=25)$ & $18.0 \pm 2.7^{\mathrm{a}}$ & 16.1 & 18.9 & $10.3 \pm 0.7^{\mathrm{a}}$ & $4.5 \pm 1.1^{\mathrm{a}}$ & $5.5 \pm 0.6^{\mathrm{a}}$ & $203 \pm 58.6^{\mathrm{a}}$ \\
\hline $2014(n=22)$ & $17.1 \pm 2.1^{\mathrm{a}}$ & 15.6 & 18.7 & $9.3 \pm 0.8^{\mathrm{a}}$ & $3.7 \pm 0.5^{\mathrm{a}}$ & $5.3 \pm 0.5^{\mathrm{a}}$ & $182 \pm 42.0^{\mathrm{a}}$ \\
\hline $2015(n=13)$ & $17.7 \pm 2.2^{\mathrm{a}}$ & 17.2 & 18.8 & $9.1 \pm 0.8^{\mathrm{a}}$ & $3.7 \pm 0.3^{\mathrm{a}}$ & $5.4 \pm 0.5^{\mathrm{a}}$ & $189 \pm 52.3^{\mathrm{a}}$ \\
\hline $2016(n=11)$ & $17.7 \pm 1.6^{\mathrm{a}}$ & 16.8 & 18.8 & $9.5 \pm 0.5^{\mathrm{a}}$ & $4.0 \pm 0.1^{\mathrm{a}}$ & $5.4 \pm 0.5^{\mathrm{a}}$ & $194 \pm 31.8^{\mathrm{a}}$ \\
\hline
\end{tabular}

Note: DBH, diameter at breast height; $Q_{1}, 1^{\text {st }}$ quartile of DBH; $Q_{3}, 3^{\text {rd }}$ quartile of DBH; $H$, tree height; $H_{\mathrm{b}}$, height of the first live branch; $\mathrm{SW}$, sapwood width; $A_{\mathrm{s}}$, sapwood area; SD, standard deviation. $n$ is the number of sample trees. Different lowercase letters within a column among different years indicate significant difference at $P<0.05$ level.

\subsubsection{Meteorological variable measurements}

Meteorological variables, including global solar radiation $\left(R_{\mathrm{s}}\right)$, net radiation $\left(R_{\mathrm{n}}\right)$, air temperature $\left(T_{\mathrm{a}}\right)$, relative humidity $(\mathrm{RH})$, wind speed $(u)$ and precipitation $(P)$, were measured using an automatic weather station (AR5, Avalon Scientific, Inc., USA) located $50 \mathrm{~m}$ away from the experimental plot. All sensors were installed at $2.0 \mathrm{~m}$ above the ground except the rain gauge that was placed at $0.5 \mathrm{~m}$ above the ground. Variables were measured at 10 -min intervals and then averaged and recorded per hour. We calculated reference evapotranspiration $\left(\mathrm{ET}_{0}\right)$ using the FAO Penman-Monteith equation based on the variables of $R_{\mathrm{n}}, T_{\mathrm{a}}, R H$ and $u$ on an hourly data (Eq. 1; Allen et al., 1998):

$$
\mathrm{ET}_{0}=\frac{0.408\left(R_{\mathrm{n}}-G\right)+\gamma \frac{900}{T_{\mathrm{a}}+273} u_{2}\left(e_{\mathrm{s}}-e_{\mathrm{a}}\right)}{\Delta+\gamma\left(1+0.34 u_{2}\right)},
$$

where $\mathrm{ET}_{0}$ is the reference evapotranspiration $(\mathrm{mm} / \mathrm{h}) ; \Delta$ is the slope of saturated water vapor pressure against air temperature $T_{\mathrm{a}}\left(\mathrm{kPa} /{ }^{\circ} \mathrm{C}\right) ; R_{\mathrm{n}}$ is the net radiation $\left(\mathrm{MJ} / \mathrm{m}^{2}\right) ; G$ is the soil heat flux $\left(\mathrm{MJ} / \mathrm{m}^{2}\right) ; \gamma$ is the psychrometric constant $\left(\mathrm{kPa} /{ }^{\circ} \mathrm{C}\right) ; e_{\mathrm{s}}$ is the saturated vapor pressure $(\mathrm{kPa}) ; e_{\mathrm{a}}$ is the actual vapor pressure $(\mathrm{kPa})$; and $u_{2}$ is the mean wind speed at a $2.0-\mathrm{m}$ height $(\mathrm{m} / \mathrm{s})$.

\subsubsection{Soil moisture and groundwater level measurements}

Three sets of soil moisture observation device were equipped at three locations in the experimental plot (Fig. 2). Soil moisture sensors $\left(\mathrm{ECH}_{2} \mathrm{O}\right.$ EC-5 sensor, Decagon Devices Inc., USA) of a set were inserted at soil depths of $0.2,0.4,0.6,0.8,1.0,1.2,1.6$ and $2.0 \mathrm{~m}$ in each location. Soil moisture $(\theta, \%)$ was measured at 10 -min intervals with hourly means recorded by a SQ2020 data logger (Grant Instruments Ltd., UK). We calibrated the data using a site-specific equation based on oven-drying method. Relative extractable soil water (REW, dimensionless) was calculated using Equation 2 (Granier, 1987):

$$
\mathrm{REW}=\frac{\bar{\theta}-\theta_{\min }}{\theta_{\mathrm{fc}}-\theta_{\min }},
$$

where $\theta_{\mathrm{fc}}(\%)$ is the field capacity that was $18.0 \%$ in the $0.0-2.0 \mathrm{~m}$ soil depth based on field observations; $\theta_{\min }$ is the minimum soil moisture during the experimental period $(2.3 \%)$; and $\bar{\theta}$ is the mean value of soil moisture from the corresponding soil layer (\%). We classified soil droughts based on REW in the top $1 \mathrm{~m}$ soil layer and growth traits of MSPs obtained from other studies near the experimental plot, and classifications of soil drought are given in Table 2. We manually monitored groundwater level $\left(g_{\mathrm{w}}\right)$ in situ once a month.

\subsubsection{Sap flow measurement and tree water use calculation}

Sap flux density in the outermost sapwood layer $\left(0-3 \mathrm{~cm}\right.$ width, $\left.J_{\text {s-outer }}, \mathrm{cm} / \mathrm{s}\right)$ was continuously measured using Granier-type thermal dissipation probes (Dynamax Inc., Houston, TX, USA). Sap flow sensors were installed in each tree in 2013. Each probe was installed under the cambium on northern side of the stem at breast height ( $1.30 \mathrm{~m}$ above ground) with pairs of probes spaced 0.04 $\mathrm{m}$ apart vertically. The upper probe was heated and the lower probe was not heated for a reference. We carefully removed each sensor at the end of each growing season (November) and reinstalled 
Table 2 Classification of soil drought based on relative extractable soil water (REW) and referenced growth trait of Mongolian Scots pine (MSP)

\begin{tabular}{ccccc}
\hline Degree of drought & REW & Soil moisture (\%) & Growth trait of MSP & Reference \\
\hline Non-drought & $\mathrm{REW}_{0-1 \mathrm{~m}}>0.31$ & $\bar{\theta}_{0-1 \mathrm{~m}}>0.4 \theta_{\mathrm{fc}}$ & Normal growth & Jiao (2001) \\
Slight drought & $0.20<\mathrm{REW}_{0-1 \mathrm{~m}} \leq 0.31$ & $0.3 \theta_{\mathrm{fc}}<\bar{\theta}_{0-1 \mathrm{~m}} \leq 0.4 \theta_{\mathrm{fc}}$ & Weak growth & Zhu et al. (2005) \\
Moderate drought & $0.08<\mathrm{REW}_{0-1 \mathrm{~m} \leq 0.20}$ & $0.2 \theta_{\mathrm{fc}}<\bar{\theta}_{0-1 \mathrm{~m} \leq 0.3 \theta_{\mathrm{fc}}}$ & $30 \%$ of leaves withered & Zhu et al. (2005) \\
Severe drought & $\mathrm{REW}_{0-1 \mathrm{~m} \leq 0.08}$ & $\bar{\theta}_{0-1 \mathrm{~m} \leq 0.2 \theta_{\mathrm{fc}}}$ & $\begin{array}{c}\text { Withered leaves and some dead } \\
\text { branches }\end{array}$ & Tang et al. (2015) \\
\hline
\end{tabular}

Note: $\bar{\theta}_{0-1 \mathrm{~m}}$ is the mean soil moisture in the $0-1 \mathrm{~m}$ soil layer (\%). $\theta_{\mathrm{fc}}$ is the field capacity $(\%)$.

near the initial position at the beginning of the next growing season (April). Temperature difference between the upper (heated) probe and the lower (referenced) probe was measured at 1-min intervals, with mean values recorded at 10-min intervals using SQ2020 data loggers. The sensors were shielded with a thick aluminum-faced foam to minimize warming by radiation and exposure to rain as well as physical damage. The Granier empirical equation for $J_{\text {s-outer }}$ is given in Equation 3:

$$
J_{\text {s-outer }}=119 \times 10^{-4}\left(\frac{\Delta T_{0}-\Delta T}{\Delta T}\right)^{1.231},
$$

where $\Delta T$ is the actual temperature difference observed between heated and referenced probes $\left({ }^{\circ} \mathrm{C}\right)$; and $\Delta T_{0}$ is the maximum $\Delta T$ value $\left({ }^{\circ} \mathrm{C}\right)$ when sap flow is close to zero, which was determined over approximately 10 consecutive days by linear regression (Lu et al., 2004; Dang et al., 2014).

Sap flux density in the inner part of sapwood (beyond $3 \mathrm{~cm}$ width, $J_{\text {s-inner }}, \mathrm{cm} / \mathrm{s}$ ) is low due to a relative inactivity of xylem, so a coefficient of 0.56 from Scots pine (Pinus sylvestris L.) was adopted following Nadezhdina et al. (2002) and Lu et al. (2004) to estimate $J_{\text {s-inner }}$.

Sap flow $\left(J_{\mathrm{t}}, \mathrm{cm}^{3} / \mathrm{h}\right)$ of whole tree was calculated by multiplying sap flux density by corresponding sapwood area on an hourly scale. Then, hourly sap flow was summed to the daily data (Eq. 4). Daily $J_{\mathrm{t}}$ was then used to estimate daily tree water use (daily $T_{\mathrm{s}}, \mathrm{mm} / \mathrm{d}$ ) using Equation 5. Considering that trees were at the same age and evenly spaced, we estimated daily $T_{\mathrm{s}}$ as the product of average sap flux density of all sample trees with cumulative sapwood area $\left(A_{\text {s-stand }}, \mathrm{m}^{2}\right)$ divided by total stand ground area $\left(A_{\mathrm{g} \text {-stand }}, \mathrm{m}^{2}\right)$ according to Clausnitzer et al. (2011).

$$
\begin{gathered}
J_{\mathrm{t}, i j}=\left(J_{\mathrm{s}-\text { outer }, i j} \times A_{\mathrm{s}-\text { outer }, i}+J_{\mathrm{s}-\text { inner }, i j} \times A_{\mathrm{s} \text {-inner }, i}\right) \times 3600, \\
T_{s}=\frac{A_{\mathrm{s}-\mathrm{stand}}}{A_{\mathrm{g}-\mathrm{stand}}} \frac{1}{\sum_{i=1}^{n} A_{\mathrm{s}, i}} \sum_{i=1}^{n} \sum_{j=1}^{24} J_{\mathrm{t}, i j},
\end{gathered}
$$

where $J_{\mathrm{t}, i j}$ is the hourly sap flow of tree $i$ at hour $j$ in a day $\left(\mathrm{cm}^{3} / \mathrm{h}\right) ; J_{\mathrm{s} \text {-outer, } i j}$ and $J_{\mathrm{s} \text {-inner, } i j}$ are the sap flux densities in the outermost sapwood layer and inner sapwood layer, respectively, of tree $i$ at hour $j$ in a day $(\mathrm{cm} / \mathrm{h}) ; A_{\mathrm{s}-\text { outer }, i}$ and $A_{\mathrm{s} \text {-inner, } i}$ represent the sapwood area of outer $3 \mathrm{~cm}$ width and the remaining sapwood area of tree $i$, respectively $\left(\mathrm{m}^{2}\right) ; A_{\mathrm{s}, i}$ equals the sum of $A_{\mathrm{s} \text {-outer, } i}$ and $A_{\mathrm{s} \text {-inner }, i}$ $\left(\mathrm{m}^{2}\right) ; n$ is the numbers of sample trees in each year; $A_{\mathrm{s}-\mathrm{stand}}$ is the total sapwood area of the 25 sample trees $\left(\mathrm{m}^{2}\right)$; and $A_{\mathrm{g} \text {-stand }}$ is the total ground area of the plot $\left(\mathrm{m}^{2}\right)$.

\subsection{Statistical analyses}

We normalized hourly and daily $T_{\mathrm{s}}$ values by their maximum values over the entire experimental period (i.e., $T_{\mathrm{s}} / T_{\mathrm{s}-\mathrm{max}}$ ) according to Whitley et al. (2008) and Clausnitzer et al. (2011) for further comparison of relative tree water use in different years. We calculated the ratio of daily tree water use to reference evapotranspiration $\left(T_{\mathrm{s}} / \mathrm{ET}_{0}\right)$ according to Labędzki and Kanecka (2009) and Fu et al. (2016) to eliminate the influence of meteorological factor. Effect of soil moisture on $T_{\mathrm{s}} / T_{\mathrm{s}-\max }$ or $T_{\mathrm{s}} / \mathrm{ET}_{0}$ was tested by one-way analysis of variance (ANOVA) and a Tukey honestly significant difference (HSD) test using SPSS 20 (SPSS Inc., Chicago, IL, USA). Significant correlations between $T_{\mathrm{s}} / T_{\mathrm{s}-\max }$ or $T_{\mathrm{s}} / \mathrm{ET}_{0}$ and environmental variables were determined by Pearson's correction coefficient tests at $P<0.05$ or $P<0.01$ level. OriginPro 2020 version 9.7 (OriginLan Inc., Northampton, MA, USA) was used for plotting. 


\section{Results}

\subsection{Seasonal dynamics of daily tree water use and environmental variables}

Amounts of precipitation in 2013, 2014, 2015 and 2016 were 554.0, 384.0, 408.0 and $623.6 \mathrm{~mm}$, respectively, showing great inter-annual variations. Using mean annual precipitation $(475.0 \mathrm{~mm})$ as a baseline, we calculated precipitation anomalies over the study period. We defined 2013 as a normal year, 2014 and 2015 as dry years, and 2016 as a wet year. However, precipitation in a year is concentrated over quite short periods, resulting in high inter-monthly variations in water supply (Fig. 3a). Thus, high amount of annual precipitation does not always guarantee enough available soil water for plants during the growing season.

REW exhibited substantial temporal variations. Heterogeneity of REW between the upper $0-1$ $\mathrm{m}$ soil layer $\left(\operatorname{REW}_{0-1 \mathrm{~m}}\right)$ and lower 1-2 m soil layer $\left(\operatorname{REW}_{1-2} \mathrm{~m}\right)$ was significant $(P<0.01)$, with $\mathrm{REW}_{0-1 \mathrm{~m}}$ being higher than REW $\mathrm{R}_{1-2 \mathrm{~m}}$. REW decreased from 2013 to 2015, especially in 2014. Values of $\mathrm{REW}_{0-1 \mathrm{~m}}$ in the dry years $(2014$ and 2015) ranged from 0.29 to 0.30 that is distinctively lower than those of in the normal year $(2013 ; 0.48)$ and the wet year $(2016 ; 0.50)$. Statistically, number of days under drought (i.e., $\mathrm{REW}_{0-1 \mathrm{~m}} \leq 0.31$; Table 2) in 2013, 2014, 2015 and 2016 accounted for $8 \%, 62 \%, 50 \%$ and $16 \%$ of the whole year, respectively. In particular, the number of severe drought was 19 d, followed by 45 d moderate drought in 2015 (Fig. 3b). Drought is expected to impose serious water stress for the growth of MSPs. For the value of REW $1-2 \mathrm{~m}$, the percentage of severe drought (i.e., $\mathrm{REW}_{1-2 \mathrm{~m}} \leq 0.08$; Table 2) accounted for $19 \%$ in 2013 and $2 \%$ in 2016 , but as more as $86 \%$ in the first dry year (2014) and 50\% in the second dry year (2015).

$R_{\mathrm{S}}$ was not significantly different among different years, with the mean values varying from 170.3 to $182.3 \mathrm{~W} / \mathrm{m}^{2}$ ( $P=0.40$; Fig. $3 \mathrm{c}$ ). $g_{\mathrm{w}}$ in 2013 was $4.88 \mathrm{~m}$ but significantly decreased to 5.82 $\mathrm{m}$ in 2016 (Fig. 3d). A slight increase in $g_{\mathrm{w}}$ due to heavy precipitation was occasionally observed in each year, but overall, $g_{\mathrm{w}}$ declined over the entire study period.

Daily $T_{\mathrm{s}} / T_{\mathrm{s}-\max }$ was significantly different $(P<0.01)$ among different years. Daily $T_{\mathrm{s}} / T_{\mathrm{s}-\max }$ was 0.21 in 2013, followed by a decrease of $25 \%$ in 2014 and a further decrease of $58 \%$ in 2015 and a decrease of $52 \%$ in 2016 . The maximum daily $T_{\mathrm{s}} / T_{\mathrm{s}-\max }$ in 2013 was 1.00 , which decreased to 0.61 , 0.32 and 0.55 in 2014, 2015 and 2016, respectively (Fig. 3e).

\subsection{REW $_{0-1 \mathrm{~m}}$ change trends in rainless episodes}

A total of 22 rainless episodes with durations ranging from 7 to $37 \mathrm{~d}$ were recorded over the studied period, in which 8 typical rainless episodes with the distinguishable initial values of $\mathrm{REW}_{0-1 \mathrm{~m}}$ were plotted to display the change trend of $\mathrm{REW}_{0-1 \mathrm{~m}}$ with cumulative daily $\mathrm{ET}_{0}$ (Fig. 4a). We found that soil moisture decreased with cumulative daily $\mathrm{ET}_{0}$ more rapidly for wet soil than for dry soil. For instance, when soil was well wetted by heavy precipitation with an initial $\mathrm{REW}_{0-1 \mathrm{~m}}$ as high as 0.94 (DOY 197-208 in 2013), the value of $\mathrm{REW}_{0-1 \mathrm{~m}}$ decreased at a rate of 0.69 per $100 \mathrm{~mm}$ of cumulative daily $\mathrm{ET}_{0}$ during 12 rainless days. For episodes with an initial $\mathrm{REW}_{0-1 \mathrm{~m}}$ of 0.41 (DOY 182-201 in 2016) and only approximately 0.13 (DOY 212-230 in 2015), the mean decline rates of $\mathrm{REW}_{0-1 \mathrm{~m}}$ was about 0.25 per $100 \mathrm{~mm}$ of cumulative daily $\mathrm{ET}_{0}$ during 20 rainless days and 0.08 per $100 \mathrm{~mm}$ of cumulative daily $\mathrm{ET}_{0}$ during 19 rainless days, respectively. The rate of decrease in the $\mathrm{REW}_{0-1 \mathrm{~m}}$ value with cumulative daily $\mathrm{ET}_{0}$ in all episodes were negatively related to the decrease in the initial value of $\mathrm{REW}_{0-1 \mathrm{~m}}$ (Fig. $4 \mathrm{~b}$ ).

\subsection{Response of daily $\boldsymbol{T}_{\mathrm{s}} / \mathbf{E T}_{\mathbf{0}}$ to soil water availability}

Daily ratio of $T_{\mathrm{s}}$ to $\mathrm{ET}_{0}$ ( $T_{\mathrm{s}} / \mathrm{ET}_{0}$, dimensionless) was used to elucidate the influence of meteorological factors. The $T_{\mathrm{s}} / \mathrm{ET}_{0}$ values during daytime on sunny days varied with soil moisture and drought levels were plotted in Figure 5. Generally, $T_{\mathrm{s}} / \mathrm{ET}_{0}$ annually decreased, and the regression slopes relative to $\mathrm{REW}_{0-1} \mathrm{~m}$ were greater in dry years than in wet years (Fig. 5a). Furthermore, mean $T_{\mathrm{s}} / \mathrm{ET}_{0}$ annually decreased under the same drought level (Fig. 5b) $(P<0.01)$. 


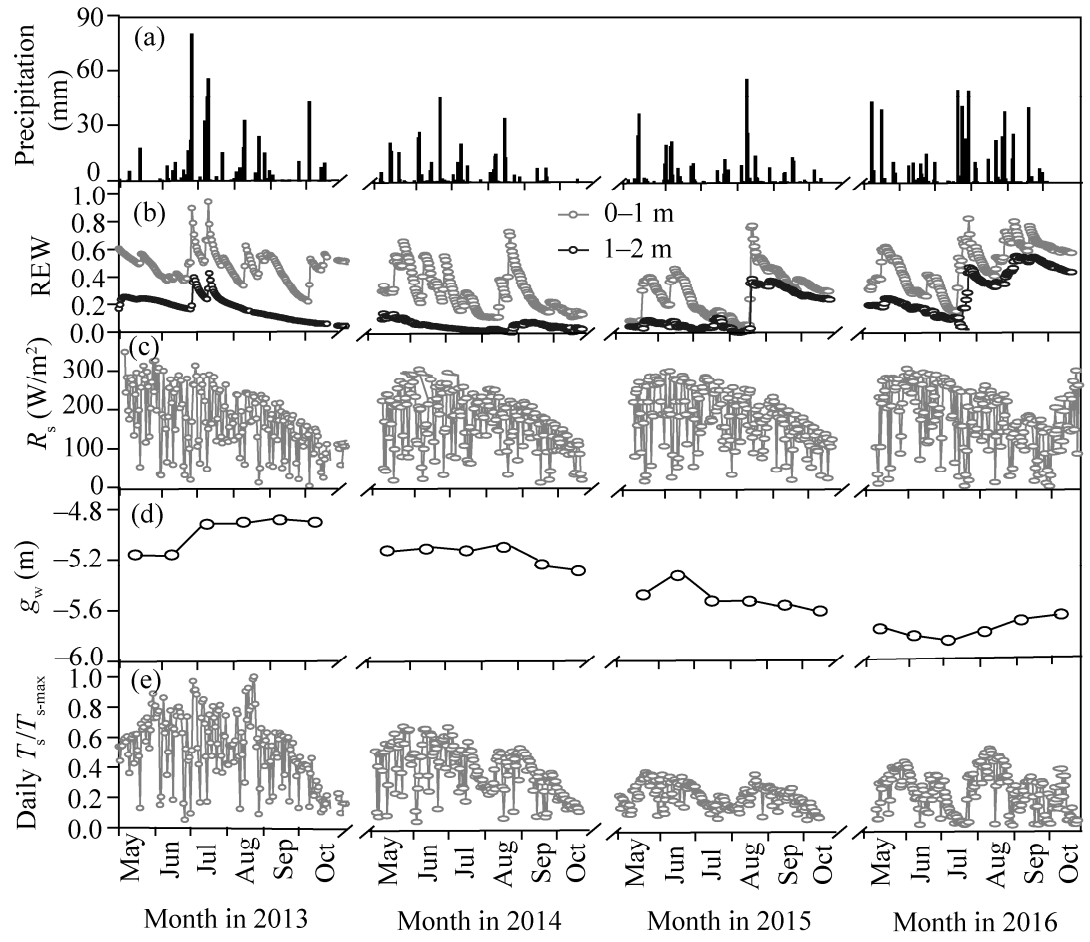

Fig. 3 Seasonal dynamics of (a) precipitation, (b) relative extractable soil water (REW), (c) solar radiation $\left(R_{\mathrm{s}}\right)$, (d) groundwater level $\left(g_{\mathrm{w}}\right)$ and (e) normalized daily tree water use (daily $T_{\mathrm{s}} / T_{\mathrm{s}-\mathrm{max}}$ ) during 2013-2016
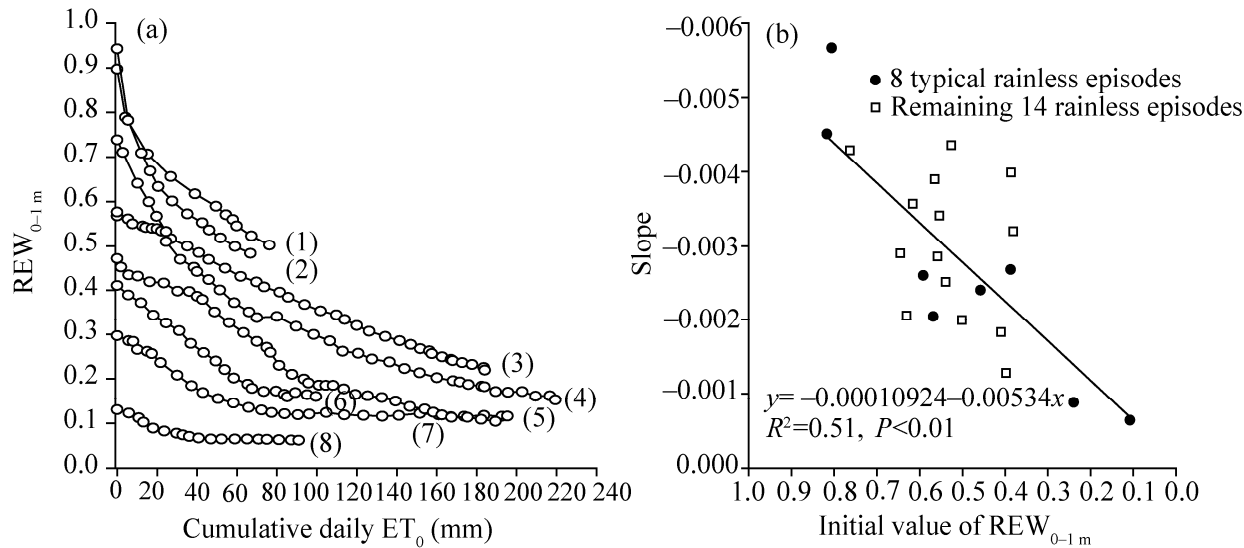

Fig. 4 (a) Relationship between relative extractable soil water in the upper $0-1 \mathrm{~m}$ layer $\left(\mathrm{REW}_{0-1 \mathrm{~m}}\right)$ and cumulative daily reference evapotranspiration $\left(\mathrm{ET}_{0}\right)$ during 8 typical rainless episodes selected from a total of 22 rainless episodes during 2013-2016, represented by the day of year (DOY) from (1) DOY 197-208 in 2013, (2) DOY 183-193 in 2013, (3) DOY 137-274 in 2014, (4) DOY 246-282 in 2013, (5) DOY 162-198 in 2015, (6) DOY 182-201 in 2016, (7) DOY 198-226 in 2014 and (8) DOY 212-230 in 2015; (b) Relationship between regression slope of $\mathrm{REW}_{0-1 \mathrm{~m}}$ relative to $\mathrm{ET}_{0}$ (from 22 rainless episodes based on linear fitting) and the initial value of $\mathrm{REW}_{0-1 \mathrm{~m}}$.

The value of $T_{\mathrm{s}} / \mathrm{ET}_{0}$ ratio under non-drought condition was $0.28( \pm 0.12)$ in 2013 , and it decreased to $0.21( \pm 0.09)$ in 2014 and $0.11( \pm 0.05)$ in 2015 , but slightly recovered to $0.14( \pm 0.08)$ in 2016 . Particularly, after two consecutive dry years, $T_{\mathrm{s}} / \mathrm{ET}_{0}$ ratio under moderate drought conditions was as low as $0.03( \pm 0.01)$ in 2016, which was even lower than that under severe in 2015, indicating dramatically reduced tree water use after prolonged droughts. Within a year, the daily $T_{\mathrm{s}} / \mathrm{ET}_{0}$ ratio at different drought levels showed a significant difference $(P<0.01)$, except in the first dry year $(P=0.57)$. 


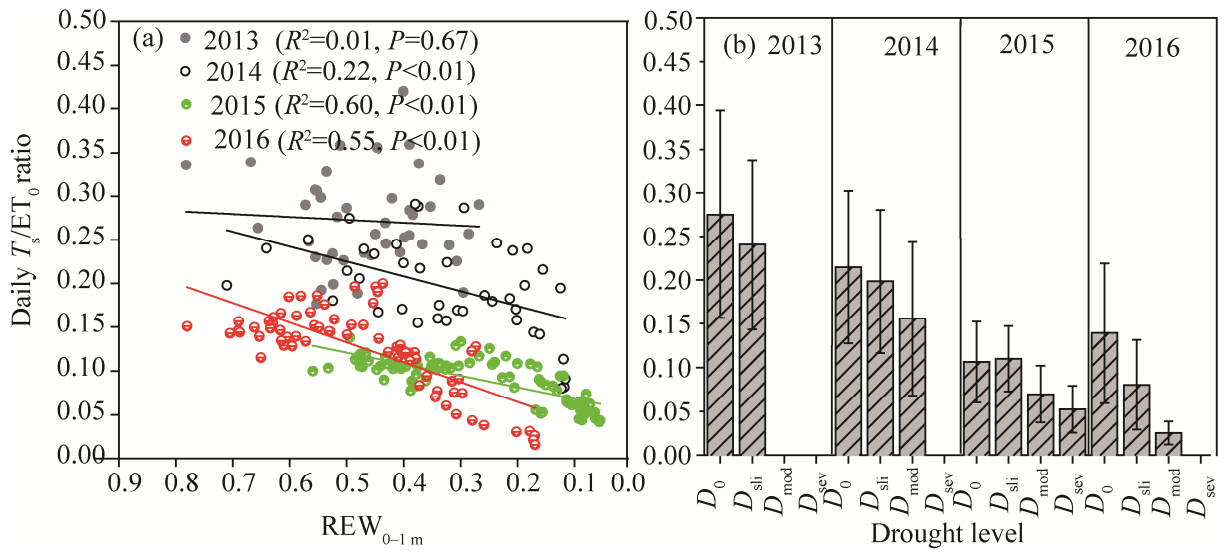

Fig. 5 (a) Relationship between daily ratio of tree water use to reference evapotranspiration $\left(T_{\mathrm{s}} / \mathrm{ET}_{0}\right)$ and relative extractable soil water in the upper 0-1 m soil depth $\left(\mathrm{REW}_{0-1 \mathrm{~m}}\right)$ during 2013-2016; (b) $T_{\mathrm{s}} / \mathrm{ET}_{0}$ ratios at different drought levels in each year. Bars indicate standard deviations. $D_{0}$, non-drought; $D_{\text {sli }}$, slight drought; $D_{\text {mod }}$, moderate drought; $D_{\text {sev }}$, severe drought.

\subsection{Recovery abilities of tree water use after prolonged drought periods}

Two typical sunny days with soil moisture under drought and rewetted conditions after heavy rains in each year were used to compare the patterns of hourly $T_{\mathrm{s}} / T_{\mathrm{s}-\max }$. On a slight drought day (DOY 282) in 2013, the maximum hourly $T_{\mathrm{s}} / T_{\mathrm{s}-\max }$ was 0.55 (Fig. 6a) and slightly recovered to 0.57 on a non-drought day (DOY 285) after a $42.4 \mathrm{~mm}$ precipitation event. In 2014, the maximum hourly $T_{\mathrm{s}} / T_{\mathrm{s}-\max }$ increased from 0.30 in a moderate drought day (DOY 224) to 0.54 in a non-drought day (DOY 238) after an $84.4 \mathrm{~mm}$ rainfall event (Fig. 6b). However, the maximum hourly $T_{\mathrm{s}} / T_{\mathrm{s}-\max }$ on a severe drought day decreased to 0.14 (DOY 228 in 2015; Fig. 6c) and 0.05 (DOY 196 in 2016; Fig. 6d). Moreover, even if the soil was well rewetted by precipitation in the dry years, the maximum hourly $T_{\mathrm{s}} / T_{\mathrm{s}-\max }$ in 2015 (DOY 237) and in 2016 (DOY 207) accounted for only $44 \%$ and $70 \%$ of that in 2013 , respectively, which indicated a reduced recovery ability of MSPs regarding tree water use under prolonged and severe droughts.

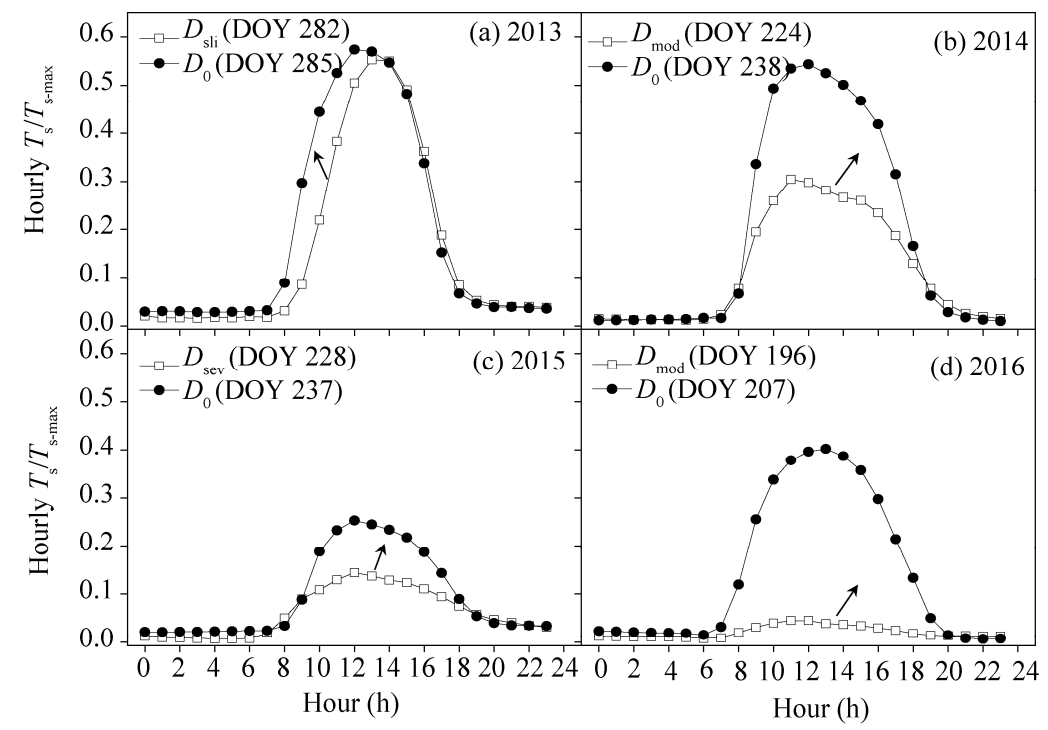

Fig. 6 Comparison of normalized hourly water use (hourly $T_{\mathrm{s}} / T_{\mathrm{s}-\mathrm{max}}$ ) on a typical sunny (drought) day with that on a typical rewetted and drought-free sunny day. It should be noted that these two days selected in a year are most likely to be close in time. Squares indicate a drought day (slight drought $\left(D_{\text {sli }}\right)$ in 2013 , moderate droughts $\left(D_{\text {mod }}\right)$ in 2014 and 2016, and severe drought $\left(D_{\text {sev }}\right)$ in 2015), and circles indicate a non-drought day after precipitation $\left(D_{0}\right)$. The arrows indicate the transition from drought to non-drought. 


\subsection{Relationship between $\boldsymbol{T}_{\mathrm{s}} / \mathbf{E T}_{\mathbf{0}}$ and groundwater level}

To further explore the reasons for suppressed tree water use after prolonged and severe droughts, we analyzed the relationship between $T_{\mathrm{s}} / \mathrm{ET}_{0}$ and groundwater levels over the studied period. We found that $T_{\mathrm{s}} / \mathrm{ET}_{0}$ ratio on sunny days generally showed a negative linear relationship with groundwater levels (Fig. 7). In the first two years, $g_{w}$ was maintained at a relatively high level, varying from 4.88 to $5.27 \mathrm{~m}$, and $T_{\mathrm{s}} / \mathrm{ET}_{0}$ ratio varied from 0.17 to 0.38 . However, in 2015 and $2016, g_{\mathrm{w}}$ decreased from 5.32 to $5.78 \mathrm{~m}$, and $T_{\mathrm{s}} / \mathrm{ET}_{0}$ ratio decreased from 0.18 to 0.06 . The suppressed $T_{\mathrm{s}} / \mathrm{ET}_{0}$ even under well rewetted soil conditions in 2016 was consistent with the findings of the continuous decline in the groundwater levels.

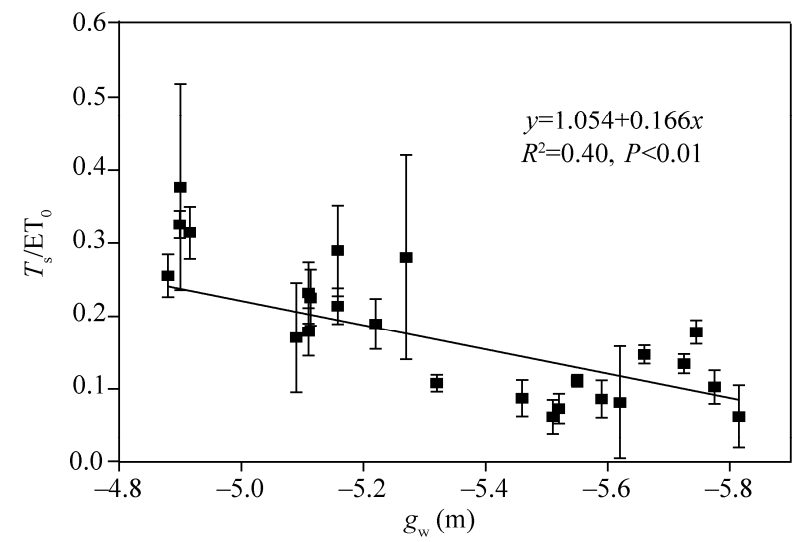

Fig. 7 Relationship between ratio of tree water use to reference evapotranspiration $\left(T_{\mathrm{s}} / \mathrm{ET}_{0}\right)$ on sunny days and groundwater $\left(g_{\mathrm{w}}\right)$ levels during 2013-2016. Bars indicate standard deviations.

\section{Discussion}

\subsection{Reduction and incomplete recovery of tree water use after droughts}

In this study, moderate drought in the first dry year (2014) and further severe drought in the second dry year (2015) resulted in a marked decline in the water use of MSP. Compared with the normal year (2013), the daily $T_{\mathrm{s}} / T_{\mathrm{s}-\max }$ was decreased by $32 \%$ in 2014 and $62 \%$ in 2015 . The significant reduction in tree water use under drought conditions reflected the conservation of MSP in water consumption. This is consistent with the findings on Scots pine trees that have a very strong plastic response to intermittent drought (Levitt, 1980; Arneth et al., 2006; Verbeeck et al., 2007; Mereu et al., 2009). It was reported that the main water source for MSP was from soil moisture in the upper soils (Su et al., 2006; Wei et al., 2013; Song et al., 2014). This result was supported by our findings that water use of MSP was mainly dependent on soil moisture in the upper $0-1 \mathrm{~m}$ soil layer. In general, the value of $T_{\mathrm{s}} / \mathrm{ET}_{0}$ ratio linearly decreased with the decline of $\mathrm{REW}_{0-1 \mathrm{~m}}$ in each year, and the slopes were more negative in the years within and after severe drought than in the normal year (2013) (Fig. 5). Therefore, water availability in the 0-1 m soil layer is important for the water use of MSP due to the shallow-rooted traits of MSP that $85 \%$ roots of MSP are occurred in the 0.0-0.4 m soil layer (Jiang et al., 2002; Zhu et al., 2005; Zhu et al., 2008).

Although rapid recovery of water use of MSP sporadically occurred with increasing soil moisture after effective precipitation, the degree of recovery in the dry years (2014 and 2015) was lower than that in the normal year (2013) (Fig. 6). However, the maximum daily $T_{\mathrm{s}} / T_{\mathrm{s} \text {-max }}$ in the wet year (2016) that was expected to completely recover due to the high annual precipitation amount accounted for only $52 \%$ of that in the normal year. Water use of MSP in two successive dry years could not recovery to the normal year (2013) (Fig. 3e). The incomplete recovery of water use of MSP under the non-drought conditions in 2016 could be attributed to the variation in hourly $T_{\mathrm{s}} / \mathrm{ET}_{0}$ that accounted for $89 \%$ of that in 2013 . This result is consistent with the reports that changes in soil moisture affect water use, but the constraints likely remain over a long period 
after droughts (Yan et al., 2016). It is previously reported that fine roots of Scots pine die quickly under drought conditions (Vanguelova and Kennedy, 2007), which might be the main direct cause of the decline in water use capacity even after soil water status was recovered.

\subsection{Effects of groundwater on tree water use under prolonged drought conditions}

A deep taproot enables trees to use water from deep soils and/or groundwater under drought conditions (Barbeta et al., 2015; Hentschel et al., 2016). MSP is a dimorphic-rooted species with a maximum taproot depth of $5.20 \mathrm{~m}$, which was observed in a 42-year-old tree in sandy soil near our site (Jiang et al., 2002). The water absorption by the deeper taproots of MSP was measured by isotopic technique when soil water content in the upper $0.6 \mathrm{~m}$ soil layer declined to $3.6 \%$ (Wei et al., 2013; Song et al., 2016a). This finding was supported by our results of the extreme depletion of soil water in the 1-2 m soil layer. Meanwhile, $g_{\mathrm{w}}$ value decreased from 4.88 to $5.82 \mathrm{~m}$ over the studied period, and in 2014, $g_{\mathrm{w}}$ value was much lower than the maximum depth of taproot $(5.20 \mathrm{~m})$. Considering the findings that $T_{\mathrm{s}} / \mathrm{ET}_{0}$ ratio during the daytime on sunny days decreased linearly with the decline in groundwater levels (Fig. 7), we concluded that significant decline in groundwater levels was partly responsible for the reduced tree water use even when soil water availability was gradually recovered. The impact of groundwater on tree water use was most prominent under extensive and prolonged drought conditions, which was greatly but incompletely replaced by rewetted upper soil. The results from MSP in this study are consistent with the report that dependence of trees on groundwater increases as precipitation decreases (Kume et al., 2007).

\subsection{Effects of soil texture on soil drought}

Sandy soils are characterized by a low water-holding capacity and high hydraulic conductivity. Therefore, these soils provide a harsh environment for plant growth. Although soil moisture in the upper layer was easily recharged from the precipitation, it rapidly decreased in a short term even at higher initial soil moisture conditions in the sandy soil due to the soil texture and strong evaporation (Fig. 4). Therefore, droughts tended to occur more frequently in the sandy soil due to the high inter-monthly variations in precipitation. Moreover, coarse sandy soil effectively prevents capillary rise of water (less than $0.5 \mathrm{~m}$ ) (Vincke and Thiry, 2008). It is reasonable that the contribution of groundwater to upper soil moisture by capillary rise is non-significant due to $>91 \%$ sand particles in the upper $2 \mathrm{~m}$ soil layer in the studied plot. As a result, more than half of days in the dry years (2014 and 2015) were drought, which was believed to induce persistent water stress on the growth of MSP.

\subsection{Implications for management of MSP plantations under climate change}

$T_{\mathrm{s}} / \mathrm{ET}_{0}$ ratio reflects the response of tree water use to atmospheric water demand, which allows us to focus on determining the effects of soil water availability on tree transpiration. In our study, $T_{\mathrm{s}} / \mathrm{ET}_{0}$ ratio generally declined with a decrease in the upper soil moisture. $T_{\mathrm{s}} / \mathrm{ET}_{0}$ ratio also showed a significant difference between different drought levels and recovered to a certain extent when the whole soil layer was thoroughly rewetted in 2016 (Fig. 5b). This study reported the plasticity of MSP under severe drought conditions through the drastic reduction in water use. Additionally, the lateral roots of an MSP tree can extend to lengths that are approximately 0.65 times that of tree height (Jiang et al., 2002; Su et al., 2006), which also helps MSP trees to efficiently obtain water from the upper soil layer (Song et al., 2014). However, incomplete recovery of water use revealed that prolonged and severe droughts might greatly limit the ability of trees to adapt to climate change. In addition to random drought episodes that can greatly reduce water use, the progressive decline rate in the groundwater level $(1 \mathrm{~m} / \mathrm{a})$ induced by extensive and/or intensive agricultural land use and broadleaved forests plantation in the study area (Song et al., 2016b) also prevented the recovery of water use, both of which would cause a deficit in the water supply and serious degradation of forest stands if allowed to continue for two or more growing seasons. As a countermeasure against the ongoing degradation of MSP, it is more effective and more urgent to prevent unrestrained exploitation of groundwater by reducing agricultural land or converting into other land use such as coniferous forest and shrubland than by merely adjusting stand density of MSP. 


\section{Conclusions}

High inter- and intra-annual variations in precipitation and soil moisture in sandy soils led to frequent droughts in the semi-arid Horqin Sandy Land. Consequently, water use of MSP strongly responded to soil water availability, especially in the upper $1 \mathrm{~m}$ soil layer, as these trees are shallow-rooted species. Severe and prolonged soil drought greatly decreased water use of MSP in a short term. The progressive decline in groundwater restricted the degree of water use recovery in MSP even if the soil was rewetted by precipitation. Our results suggested that the degradation of MSP plantations is attributable to the high temporal variations in precipitation, low soil water retention and declining groundwater level. In addition to adjusting planting density and stand structure, preventing groundwater level from decreasing by reducing irrigated farmland area is recommended as an alternative method to stop ongoing degradation of MSP in the Horqin Sandy Land of northern China.

\section{Acknowledgements}

This work was supported by the Fundamental Research Funds for the Central Nonprofit Research Institution of Chinese Academy of Forestry (CAFYBB2014MA013), the National Natural Science Foundation of China (31570704) and the Major State Basic Research Development Program of China (2013CB429901). Field support for this research was provided by the Zhanggutai National Studies Station for the Desert Ecosystem of China.

\section{References}

Allen R G, Pereira L S, Raes D, et al. 1998. Crop evapotranspiration: Guidelines for computing crop water requirements. FAO irrigation and drainage paper 56. Rome: Food and Agriculture Organization of the United Nations.

Arneth A, Veenendaal E M, Best C, et al. 2006. Water use strategies and ecosystem-atmosphere exchange of $\mathrm{CO}_{2}$ in two highly seasonal environments. Biogeosciences, 3(4): 421-437.

Barbeta A, Mejía-Chang M, Ogaya R, et al. 2015. The combined effects of a long-term experimental drought and an extreme drought on the use of plant-water sources in a Mediterranean forest. Global Change Biology, 21(3): 1213-1225.

Bovard B D, Curtis P S, Vogel C S, et al. 2005. Environmental controls on sap flow in a northern hardwood forest. Tree Physiology, 25(1): 31-38.

Clausnitzer F, Köstner B, Schwärzel K, et al. 2011. Relationships between canopy transpiration, atmospheric conditions and soil water availability-Analyses of long-term sap-flow measurements in an old Norway spruce forest at the Ore Mountains/Germany. Agricultural and Forest Meteorology, 151(8): 1023-1034.

Dang H Z, Zha T S, Zhang J S, et al. 2014. Radial profile of sap flow velocity in mature Xinjiang poplar (Populus alba L. var. pyramidalis) in Northwest China. Journal of Arid Land, 6(5): 612-627.

D'Odorico P, Porporato A. 2006. Soil moisture dynamics in water-limited ecosystems. In: D'Odorico P, Porporato A. Dryland Ecohydrology. Netherlands: Springer, 31-46.

Fu S, Sun L, Luo Y. 2016. Combining sap flow measurements and modelling to assess water needs in an oasis farmland shelterbelt of Populus simonii Carr in Northwest China. Agricultural Water Management, 177: 172-180.

Gazol A, Camarero J J, Jiménez J J, et al. 2018. Beneath the canopy: Linking drought-induced forest die off and changes in soil properties. Forest Ecology and Management, 422(15): 294-302.

Granier A. 1987. Evaluation of transpiration in a Douglas-fir stand by means of sap flow measurements. Tree Physiology, 3(4): 309-320.

Hentschel R, Hommel R, Poschenrieder W, et al. 2016. Stomatal conductance and intrinsic water use efficiency in the drought year 2003: a case study of European beech. Trees, 30(1): 153-174.

Jiang F Q, Cao C Y, Zeng D H, et al. 2002. Degradation and Restoration of Ecosystems on Keerqin Sandy Land. Beijing: Chinese Forestry Press, 282. (in Chinese)

Jiao S R. 1989. Structure and Function of Forestry Ecosystem for Sand-fixation in Zhanggutai Area. Shenyang: Liaoning Science and Technology Press, 114. (in Chinese)

Jiao S R. 2001. Report on the causes of the early decline of Pinus slyvestris var. mongolica shelterbelt and its preventative and control measures in Zhanggutai of Liaoning Province. Scientia Silvae Sinicae, 37(2): 131-138. (in Chinese)

Kume T, Takizawa H, Yoshifuji N, et al. 2007. Impact of soil drought on sap flow and water status of evergreen trees in a tropical monsoon forest in northern Thailand. Forest Ecology and Management, 238(1): 220-230. 
Łabędzki L, Kanecka-Geszke E. 2009. Standardized evapotranspiration as an agricultural drought index. Irrigation and Drainage, 58(5): 607-616.

Leo M, Oberhuber W, Schuster R, et al. 2014. Evaluating the effect of plant water availability on inner alpine coniferous trees based on sap flow measurements. European Journal of Forest Research, 133(4): 691-698.

Levitt J. 1982. Responses of Plants to Environmental Stresses. Volume II. Water, Radiation, Salt, and Other Stresses. New York, USA: Academic Press, 607.

Lu P, Urban L, Zhao P. 2004. Granier's thermal dissipation probe (TDP) method for measuring sap flow in trees: theory and practice. Acta Botanica Sinica, 46(6): 631-646. (in Chinese)

Meinzer F C, Brooks J R, Domec J C, et al. 2006. Dynamics of water transport and storage in conifers studied with deuterium and heat tracing techniques. Plant, Cell and Environment, 29(1): 105-114.

Mereu S, Salvatori E, Fusaro L, et al. 2009. An integrated approach shows different use of water resources from Mediterranean Maquis species in a coastal dune ecosystem. Biogeosciences, 6(11): 2599-2610.

Song L N, Zhu J J, Li M C, et al. 2014. Water utilization of Pinus sylvestris var. mongolica in a sparse wood grassland in the semiarid sandy region of Northeast China. Trees, 28(4): 971-982.

Song L N, Zhu J J, Li M C, et al. 2016a. Sources of water used by Pinus sylvestris var. mongolica trees based on stable isotope measurements in a semiarid sandy region of Northeast China. Agricultural Water Management, 164: 281-290.

Song L N, Zhu J J, Li M C, et al. 2016b. Water use patterns of Pinus sylvestris var. mongolica trees of different ages in a semi-arid sandy lands of Northeast China. Environmental and Experimental Botany, 129: 94-107.

Su F L, Liu M G, Guo C J, et al. 2006. Characteristics of vertical distribution of root system of Mongolian Scotch pine growing in sandy area and influence to the soil. Soil and Water Conservation, 286: 20-23. (in Chinese)

Su H, Li Y G, Liu W, et al. 2014. Changes in water use with growth in Ulmus pumila in semiarid sandy land of northern China. Trees, 28(1): 41-52.

Tang F D, Lin Y, Li Y. 2015. Impact of water stress photosynthesis characteristics of Mongolian pine seedlings and grafting Korean pine seedlings with stocks of Mongolian pine. Journal of Liaoning University, 42(3): 274-276. (in Chinese)

Vanguelova E I, Kennedy F. 2007. Morphology, biomass and nutrient status of fine roots of Scots pine (Pinus sylvestris) as influenced by seasonal fluctuations in soil moisture and soil solution chemistry. Plant and Soil, 270(1): 233-247.

Verbeeck H, Steppe K, Nadezhdina N, et al. 2007. Model analysis of the effects of atmospheric drivers on storage water use in Scots pine. Biogeosciences, 4(4): 657-671.

Vincke C, Thiry Y. 2008. Water table is a relevant source for water uptake by a Scots pine (Pinus sylvestris L.) stand: Evidences from continuous evapotranspiration and water table monitoring. Agricultural and Forest Meteorology, 148(10): 1419-1432.

Wei Y F, Fang J, Liu S, et al. 2013. Stable isotopic observation of water use sources of Pinus sylvestris var. mongolica in Horqin Sandy Land, China. Trees, 27(5): 1249-1260.

Wesche K, Walther D, Wehrden H V, et al. 2011. Trees in the desert: Reproduction and genetic structure of fragmented Ulmus pumila forests in Mongolian drylands. Flora, 206(2): 91-99.

Whitley R, Zeppel M, Armstrong N, et al. 2008. A modified Jarvis-Stewart model for predicting stand-scale transpiration of an Australian native forest. Plant and Soil, 305(1-2): 35-47.

Yan M J, Zhang J G, He Q Y, et al. 2016. Sapflow-based stand transpiration in a semiarid natural oak forest on China's Loess Plateau. Forests, 7(10): 227-240.

Zhang J H, Wang N A, Niu Z M, et al. 2018. Stable isotope analysis of water sources for Tamarix laxa in the mega-dunes of the Badain Jaran Desert, China. Journal of Arid Land, 10(6): 821-831.

Zheng X, Zhu J J, Yan Q L, et al. 2012. Effects of land use changes on the groundwater table and the decline of Pinus sylvestris var. mongolica plantations in southern Horqin Sandy Land, Northeast China. Agricultural Water Management, 109(9): 94-106.

Zhu J J, Kang H Z, Li Z H, et al. 2005. Impact of water stress on survival and photosynthesis of Mongolian pine seedlings on sandy land. Acta Ecologica Sinica, 25: 2527-2533. (in Chinese)

Zhu J J, Li F Q, Xu M L, et al. 2008. The role of ectomycorrhizal fungi in alleviating pine decline in semiarid sandy soil of northern China: an experimental approach. Annals of Forest Science, 65(3): 304-304. 